\title{
Aspectos positivos e negativos da esterilização tubária do ponto de vista de mulheres esterilizadas
}

\author{
Positive and negative aspects of Fallopian tube \\ sterilization as viewed by sterilized women
}

Luzinete Simões Minella 1

\footnotetext{
1 Departamento de Ciências Sociais, Programa de Pós-Graduação em Sociologia Política, Universi dade Federal de Santa Catarina. Campus Universitário Trindade, C. P. 476, Florianópolis, SC 88040-900, Brasil.
}

Abstract The objective of this paper is to point out the positive and negative aspects of female sterilization as seen by two groups of sterilized women in Florianópolis, Santa Catarina, Brazil, based on a sociological discussi on of their present health status, evaluating the associations that they generally make with the fact that they have been sterilized. The first group included mostly housewives from a low-income neighborhood, while the second involved upper-middle-class female public employees, students, and university professors, totaling 40 women. Data were obtained through a structured questionnaire with open-ended questions. Information on social, economic, and demographic variables was recorded, al ong with subjective data associated with women's representations of the post-sterilization period. We concluded that there was no consensus as to the consequences of sterilization, since a number of the women (11/40), mostl y sterilized before the age of 30, perceived changes in their health status after surgery.

Key words Tubal Sterilization; Women's Health; Contraception; Social Representation

Resumo O objetivo deste artigo consiste em tratar os aspectos positivos e negativos da esterilização feminina, de acordo com o ponto de vista de dois grupos de mulheres esterilizadas em Florianópolis, Santa Catarina, Brasil, a partir de uma discussão sociológi ca sobre o seu estado de saúde atual, avaliando-se as relações que costumam fazer entre este estado e a condi ção de esterilizada. O primeiro grupo está constituído por mulheres provenientes de um bairro de baixa renda, predomi nantemente donas de casa, e o segundo grupo inclui funcionárias públicas, estudantes e professoras uni versi tárias, provenientes dos setores médios da sociedade, totalizando quarenta mulheres. A metodologia da pesqui sa baseou-se em um questionário estruturado com perguntas abertas de modo a registrar tanto aspectos li gados a variávei s sóci o-econômi cas e demográficas, quanto dados subjeti vos ligados às representações das mulheres sobre o período pósesterilização. Além de uma série de outros aspectos, tornou-se possível concluir que não existe consenso sobre as conseqüências da esterilização, tendo-se constatado a existência de uma proporção si gnificativa de mulheres esterilizadas (11) principalmente antes dos 30 anos que percebem alterações de saúde após a laqueadura.

Palavras-chave Esterilização Tubária; Saúde da Mulher; Contracepção; Representação Social 


\section{Introdução}

O objetivo desta pesquisa consiste em analisar sociologicamente as representações das muIheres esterilizadas acerca desta condição, verificando-se, de acordo com seu ponto de vista, tanto os aspectos positivos, quanto os aspectos negativos do período pós-esterilização. Neste sentido, entende-se que tais representações são construídas a partir da relação que a muIher percebe entre a realização da esterilização através da ligação de trompas e o seu estado de saúde atual.

Tal entendimento se baseia na teoria das representações sociais, que ao centrar a atenção nas relações entre sujeito e objeto do conhecimento (renunciando às idéias de um "sujeito puro" e de um "objeto puro"), "recupera um sujeito que, através de sua atividade erelação com o objeto-mundo, constrói tanto o mundo como a si próprio" (Jovchelovitch \& Guareschi, 1994:19).

Por isto mesmo, tais representações funcionam como estruturas simbólicas que nascem tanto do próprio indivíduo quanto dos inúmeros condicionantes sociais e culturais que $o$ cercam, conformando um dinâmico e contínuo processo onde tanto o indivíduo é representado pelos demais, quanto se auto-representa e constrói suas próprias representações sobre os demais (Farr, 1994).

Realizada em Florianópolis, Santa Catarina, esta pesquisa nasceu da constatação da existência de pontos de vista diferentes sobre as conseqüências orgânicas, sociais e emocionais da esterilização feminina. Motivada por esta constatação, a reflexão sociológica adotada neste artigo baseia-se nas seguintes considerações preliminares:

1) De modo geral, a literatura sobre população e contracepção tem sido unânime em destacar o considerável avanço da prática da esterilização feminina nas últimas décadas no país, avanço este que coincide com uma tendência geral, observável principalmente entre os países em desenvolvimento.

Esta literatura tem sido unânime também em indicar que este avanço é um dos responsáveis, dentre outros fatores (o acelerado processo de urbanização, a expansão das relações capitalistas de produção e as mudanças culturais que interferem na regulação da fertilidade) pela drástica queda da fecundidade da população brasileira, observável a partir da década de 70 (Simões \& Oliveira, 1988; Costa \& Pinto, 1989; Martine, 1989; IBGE, 1994; CN, 1993; Carvalho, 1994; Berquó, 1994).

2) De modo geral sabe-se que este declínio tem se mantido acelerado, pois em 1991, de acordo com o IBGE, tem-se uma taxa de fecundidade total no país equivalente a 2,4 fil lhos por mulher, sendo que a Região Sul vem apresentando desde 1940, os índices médios mais baixos de fecundidade, constrastando visivelmente com o Norte e o Nordeste do país, principalmente. Assim por exemplo, a taxa de fecundidade da Região Sul, entre a década de 70 e a década de 80 declinou 35,0\%, (o maior percentual do país), sendo que em termos globais, entre 1980 e 1991, o nível de fecundidade da mulher brasileira apresentou um declínio equivalente a $33,0 \%$.

No caso específico de Florianópolis, constatava-se em 1986 que a taxa de fecundidade equivalia a 3,5 filhos por mulher e $27,0 \%$ das mulheres casadas, em idade reprodutiva e usuárias de contraceptivos já se encontravam esterilizadas. Embora inexistam ainda dados mais atuais acerca destes aspectos, muito provavelmente, tendo-se em vista as tendências nacionais, houve modificações neste padrão, estimando-se tanto um aumento do número de mulheres esterilizadas, quanto uma baixa ainda mais significativa da taxa de fecundidade.

3) A complexidade e a riqueza do tema reflete-se na existência de várias tendências de interpretação que se inserem principalmente no âmbito das discussões em torno aos seguintes temas principais: definição de políticas de saúde da mulher; análise crítica das práticas de saúde na área da contracepção; análise das relações entre esterilização feminina e questões de gênero, sexualidade e cultura; denúncias das estratégias informais de controle da natalidade; análise das políticas de população; e, por último, análises das ciências médicas sobre as vantagens e as desvantagens da esterilização feminina.

Os avanços realizados por estas tendências constituem o pano de fundo para as reflexões do presente estudo, cuja peculiaridade consiste em analisar sociologicamente as representações das mulheres esterilizadas acerca do período pós-esterilização, sendo mais diretamente influenciado pela segunda e terceira tendências, embora incorpore muitas das conquistas realizadas pelas demais.

Dentre os objetivos a longo prazo, destacam-se: primeiro, a necessidade de contribuir para transformar as discussões que ocorrem no âmbito privado sobre as conseqüências da esterilização, em um debate público, capaz de promover uma conscientização maior a propósito das vantagens e desvantagens da laqueadura. Isto porque entende-se que o esforço no sentido de que sejam dados (pelas instituições competentes) os devidos esclarecimentos à po- 
pulação feminina sobre estes aspectos, faz parte de uma luta mais ampla pelos direitos reprodutivos da mulher; segundo, espera-se a partir daí poder contribuir para a formulação de políticas públicas na área da contracepção, através de uma análise que, abordando a dimensão subjetiva do problema, possa subsidiar as tentativas atuais de legalização da esterilização no país, a fim de que sejam evitados os abusos (amplamente divulgados) que vêm sendo cometidos.

A realização deste estudo se justifica pois, em razão de dois fatores: o avanço indiscriminado da esterilização feminina no país e a falta de assistência e orientação médica na área da contracepção, entendendo-se que a soma destes fatores tem conduzido as mulheres a vivenciarem com mais freqüência novos tipos de risco em relação à sua saúde, riscos que resultam das práticas contraceptivas.

\section{Sujeitos e métodos}

Trata-se de um estudo qualitativo baseado na entrevista individual de 40 mulheres esterilizadas. Devido à necessidade de estabelecer comparações entre mulheres oriundas de estratos sociais distintos, a fim de poder matizar os resultados, dois grupos constituíram o universo da pesquisa: um grupo de mulheres esterilizadas proveniente de um bairro de baixa renda, predominantemente donas-de-casa e um grupo de mulheres proveniente dos setores médios, vinculado à estrutura de serviços públicos da cidade, constituído predominantemente por professoras universitárias e funcionárias públicas.

O bairro da Costeira do Pirajubaé, densamente povoado e localizado no Sul de Florianópolis, foi escolhido para a realização das entrevistas do primeiro grupo (a partir de agora identificado como Grupo I); as entrevistas do segundo grupo (a partir de agora identificado como Grupo II) foram realizadas no âmbito da Universidade Federal de Santa Catarina, no Campus Universitário da Trindade.

Para a coleta de dados elaborou-se um questionário estruturado com perguntas abertas de modo a registrar tanto aspectos ligados a variáveis sócio-econômicas e demográficas, quanto aspectos ligados à percepção das muIheres. No Grupo I foram feitas 22 entrevistas, enquanto que no Grupo II realizaram-se 18, perfazendo pois um total de 40 entrevistas.

Inicialmente havia-se considerado a possibilidade de realizar as entrevistas do Grupo I no Centro de Saúde do bairro, o qual, dentre os
54 postos municipais da Grande Florianópolis, é responsável pelo atendimento do maior número de pessoas, contando por isto mesmo, com uma equipe numerosa e diversificada, capaz de prestar atendimento a 3.000 mulheres, conforme demonstram os prontuários arquivados.

Além do mais pretendia-se tomar como ponto de partida uma pesquisa já realizada com 64 mulheres que freqüentam este Centro sobre as modificações nos padrões de contracepção após a implantação do PAISM em 1990. Os resultados desta pesquisa indicam que em 1989 a esterilização ocupava o terceiro lugar entre os métodos contraceptivos, tendo passado ao segundo lugar em 1992, numa proporção equivalente a $12,5 \%$ das usuárias. Os resultados indicam ainda que em $50 \%$ das decisões atuais sobre a utilização dos contraceptivos, tem havido influência dos profissionais de saúde (Gazola \& Boeira, 1992). Deixa-se de avaliar, no entanto, em que medida existe coerência entre as propostas programáticas do PAISM (que incluem disponibilidade de métodos, informações sobre o seu uso e acompanhamento clínico-ginecológico) e as práticas que se desenvolveram após sua implantação.

Mas, a idéia inicial de realização de uma pesquisa neste Centro, capaz de complementar estes resultados através da formulação de novos problemas vinculados mais estreitamente à condição das esterilizadas, teve de ser abandonada em função de dois fatores: primeiro, a baixíssima freqüência das mulheres esterilizadas do bairro às consultas, conduta que leva a crer que de fato, tratando-se dos setores populares, a procura pelos agentes de saúde está condicionada à existência de problemas graves; segundo, as freqüentes e às vezes prolongadas greves no setor de saúde municipal, durante o período da pesquisa, terminaram por inviabilizar de fato a utilização do Posto como local privilegiado de contato com as mulheres. Constatadas estas dificuldades as entrevistas foram realizadas nas residências das mulheres, tendo-se localizado as esterilizadas através de contatos diretos com as famílias do bairro e ainda indiretamente através de informações das entrevistadas acerca das suas vizinhas.

Em princípio esperava-se entrevistar igual número de mulheres no Grupo II. A fim de identificar as mulheres esterilizadas, foram realizados contatos informais através da reconstituição de redes de relações que vão se formando no interior dos Cursos, a partir das suas Coordenações. Mas, não obstante o contingente feminino do Campus seja expressivo e 
atualmente estimado em 9.481 mulheres ( 7.048 estudantes, 1.756 servidoras e 677 professoras), o total de entrevistas ficou abaixo de vinte e dois devido ao baixo número de esterilizadas entre as estudantes, em geral solteiras e muito jovens, e ainda devido à resistência manifestada por algumas servidoras e professoras que se esquivaram das entrevistas por considerar a questão "muito pessoal". O levantamento realizou-se em cinco cursos, Ciências Sociais, Psicologia, Serviço Social, Nutrição e História, tendo incluído professoras universitárias, funcionárias públicas e estudantes.

A proposta original desta pesquisa previa ainda a entrevista dos parceiros das mulheres investigadas, de modo a recuperar os depoimentos do casal acerca da esterilização, especialmente nos casos em que as mulheres admitissem problemas de saúde após a cirurgia. No entanto, as mulheres dos dois grupos trataram de "poupar" seus companheiros, alegando que eles "não precisavam ser entrevistados", o que leva a crer, dentre outras coisas, que além da mulher na maior parte das vezes assumir sozinha as decisões sobre a contracepção, evita ainda incomodar o parceiro com discussões sobre o assunto, principalmente quando tais discussões envolvem a presença de terceiros, estranhos à intimidade do casal.

\section{Resultados e discussão}

A análise dos dados que permitem a construção do perfil das mulheres investigadas nos dois Grupos, realizou-se de modo a recuperar em primeiro lugar as informações objetivas relativas à ocupação, idade, renda, nível de escolaridade, número de filhos, idade que tinha quando foi esterilizada, tipo de esterilização, e motivos da esterilização. Em segundo lugar, foram resgatados os depoimentos que avaliam as conseqüências orgânicas, sociais e emocionais da esterilização conforme a percepção das esterilizadas.

Considerando-se inicialmente a ocupação, verificou-se que o perfil ocupacional das entrevistadas e dos seus parceiros, coincidia com o perfil da cidade, desde quando em Florianópolis os serviços se encontram entre as atividades econômicas que mais se destacam. No caso do Grupo I prevaleceram nitidamente as donasde-casa (16), verificando-se em segundo lugar as atividades técnicas(03), em terceiro as atividades comerciais (02) e por último, uma funcionária pública. No Grupo II predominaram as professoras universitárias (06), seguidas pelas funcionárias públicas (05), 04 que concilia- vam o estudo em cursos de nível superior com as atividades domésticas, duas que estudavam e trabalhavam fora de casa e uma que apenas estudava.

Todas as mulheres entrevistadas são brancas, moravam em casa própria e suas idades variavam entre um mínimo de 25 e um máximo de 53 anos, sendo que em ambos os Grupos predominou a faixa etária compreendida entre 40 e 44 anos (06 no Grupo I e 07 no Grupo II), seguida pela faixa etária entre 35 e 39 anos, correspondendo a 05 mulheres do Grupo I e 04 do Grupo II.

Quanto ao estado civil, no Grupo I, 21 eram casadas e 01 separada, enquanto no Grupo II , 14 eram casadas, 02 amasiadas e 02 separadas.

O número de filhos variou entre o mínimo de 01 (em 02 casos) e o máximo de 08 (em dois casos, de donas-de-casa). Embora tenha-se observado maior paridade no Grupo I, (pois 08 mulheres têm a partir de quatro filhos, enquanto no Campus, apenas três se incluem neste caso), a maior parte das mulheres tinha três filhos, sendo que no Grupo II apresentouse um equilíbrio entre as que têm dois filhos (07) e as que têm três (07).

O nível de escolaridade oscilou entre o primeiro grau incompleto e a pós-graduação, observável em cinco casos. Percebeu-se uma nítida diferença entre os dois grupos, pois no Grupo I, o nível preponderante equivalia ao primeiro grau incompleto (15) enquanto no Grupo II , prevalecia o nível superior (11).

Quanto à religião prevaleceu nos dois grupos o catolicismo (32), tendo-se encontrado uma espírita e duas evangélicas no Grupo I e cinco (que se distribuem entre os dois grupos) que admitiam "não ter religião".

Tornou-se difícil precisar os dados sobre o rendimento mensal do grupo familiar porque algumas entrevistadas não informaram sobre o rendimento do cônjuge. No entanto foi possível verificar que a maioria das mulheres do Grupo I (18) situava-se na faixa entre 03 a 05 salários mínimos. O limite mínimo, presente em 03 casos nesse Grupo chegou até 01 salário mínimo. Estes baixos índices conferem tanto com a realidade do Estado de Santa Catarina quanto com a de Florianópolis onde $52,6 \%$ e $31,0 \%$ das famílias, respectivamente, tinham uma renda mensal equivalente a até dois salários mínimos em 1991 (IBGE, 1994).

No Grupo II concentraram-se os maiores rendimentos mensais, atingido pelas professoras universitárias e em geral, superior a sete salários mínimos.

Quanto à ocupação do companheiro, prevaleceu no Grupo I o setor informal, tendo-se 
verificado as seguintes ocupações: marceneiro, mecânico, mestre-de-obras, motorista, etc. além de comerciantes; enquanto isto, no Grupo II predominou o setor formal, observandose a existência de dentistas, engenheiros, técnicos, professores universitários e funcionários públicos.

O nível de escolaridade dos companheiros acompanhou, em termos gerais o das mulheres. Assim, enquanto no Grupo I, treze homens tinham apenas o primeiro grau incompleto, sendo o nível mais alto, presente em três casos, o segundo grau completo; no caso do Grupo II, predominou o nível superior (06), o grau máximo esteve representado pelo Doutorado, e o mínimo pelo segundo grau completo.

Os dados sobre o tipo de esterilização, em termos gerais, demonstraram que predominou a laparotomia ampla (feita durante cesariana), totalizando 30 mulheres, independentemente de idade, ocupação e nível de escolaridade. Apenas 04 realizaram laparoscopia (esterilização feita com endoscópio através da barriga), 04 realizaram minilaparotomia periumbilical (esterilização realizada através de pequena incisão abaixo do umbigo realizada imediatamente após o parto) e 02 realizaram minilaparotomia (cirurgia realizada através de pequena incisão acima do osso púbico), independente do parto.

O alto índice representado pela laparotomia ampla realizada durante cesariana, confirma uma tendência nacional, constatada em outros estudos. Osis et al. (1990), por exemplo, encontram em estudo realizado em São Paulo, que a maioria das mulheres (72,0\%) foram esterilizadas durante cesariana. Anteriormente, Costa et al. (1989), ao analisarem a situação das esterilizadas em favelas situadas na região metropolitana do Rio de Janeiro, haviam encontrado uma taxa equivalente a $63,0 \%$. O IBGE por sua vez, com base em dados levantados em 1986, afirmava que o percentual de esterilizações realizadas durante o último parto chegava a $75,1 \%$ no país, e a $69,6 \%$ em Santa Catarina.

Quanto ao local da cirurgia, prevaleceu nitidamente em ambos os Grupos, o hospital público, coincidindo ainda com a análise de Costa et al. (1989), que constatou em São Paulo, um índice equivalente a 73,0\%. Assim, observa-se que vinte mulheres do Grupo I e 10 do Grupo II foram esterilizadas em hospitais públicos, enquanto duas do Grupo I e duas do Grupo II foram esterilizadas em clínica particular e ainda 06 deste Grupo foram operadas em hospitais particulares.

A maior parte das mulheres (14) foi esterilizada entre os 30 e os 34 anos, onze após os 35, enquanto as demais fizeram a cirurgia quando eram demasiadamente jovens: nove entre 25 e 29 anos e seis entre 20 e 24 . Estes dados confirmam que a tendência a esterilizar mulheres jovens vem se manifestando no país como um todo de modo assustador. Os dados divulgados pelo IBGE em 1986, sobre o país e sobre Santa Catarina, já demonstravam que $15,5 \%$ das brasileiras e 5,1\% das catarinenses esterilizadas tinham realizado a cirurgia entre 15 e 24 anos; $32,0 \%$ das brasileiras e $25,4 \%$ das catarinenses entre 25 e 29 anos.

Dentre os motivos da esterilização destacou-se claramente o "não querer mais ter fiIhos" (34), uma mulher admitiu a mesma coisa e comentou que além disso "o marido não quis fazer vasectomia", enquanto cinco declararam que dois fatores pesaram igualmente: "não querer mais ter filhos" e "problemas de saúde": pressão alta, colesterol, problemas nervosos, problemas de útero e outras moléstias atribuídas ao uso prolongado da pílula. No Grupo II , de modo geral, a necessidade de evitar o aumento da família foi relacionada a fortes razões materiais, ligadas à sobrevivência do grupo familiar.

A pílula, aliás, prevaleceu como método contraceptivo mais utilizado antes, pois catorze das mulheres experimentaram apenas este método, enquanto onze alternaram a pílula, a tabela e a camisinha, independente de nível de instrução, idade e outras variáveis. Apenas uma professora universitária admitiu ter utilizado o dispositivo intra-uterino, enquanto uma outra professora experimentou o diafragma.

Esses dados constatam que o conhecimento e a prática de métodos contraceptivos naturais ou de barreira é limitado, mesmo no Grupo II, conforme demonstram os resultados das pesquisas realizadas por Almeida (1988) em Salvador, sobre status social e contracepção e Costa et al. (1989) ao analisar o padrão da contracepção no Rio de Janeiro.

Não obstante o uso dos métodos, o número de abortos que as mulheres declararam ter tido foi alto, registrando-se onze no Grupo I e nove no Grupo II, configurando-se assim uma média de 0,5 aborto por mulher.

Com relação à decisão de esterilizar-se, a maior parte das mulheres (13 no Grupo I e 09 no Grupo II) admitiu que tomou sozinha a decisão, confirmando-se neste caso que a mulher costuma assumir maior responsabilidade sobre os assuntos relativos à contracepção do que o companheiro. Em nove casos no Grupo I e em 04 casos no Grupo II, afirmou-se que "o médico influenciou na decisão". Enquanto isto, oito mulheres no Grupo I e onze no Grupo II 
admitiam que já tinham tomado a decisão quando procuraram o médico, confirmando-se deste modo tanto a existência de uma demanda voluntária das mulheres neste sentido, quanto o poder dos agentes médicos em interferir cotidianamente nos padrões de reprodução humana através do reforço a este tipo de demanda.

De modo geral, observou-se que as mulheres, principalmente as de baixa renda (Grupo I), costumam informar-se pouco sobre o próprio corpo, para isto utilizando-se de conversas com os médicos, revistas, programas de televisão, livros e a Bíblia (01 caso). Este fato se refletiu em outros aspectos, por exemplo, nas informações sobre a esterilização: no Grupo I, a grande maioria (20) e no Grupo II uma significativa parcela (8), jamais perguntou aos agentes médicos sobre possíveis conseqüências para a saúde. Apenas em cinco casos o "médico admitiu que podia haver problema".

A maior parte delas consentiu que fosse realizada a cirurgia (39), observando-se, porém, um caso em que a esterilização foi realizada sem o consentimento da paciente.

Trata-se de uma mulher encontrada no Grupo I atualmente com 53 anos, oito filhos, esterilizada aos quarenta. Segundo ela, "o médico contou da ligadura seis dias após a cesariana. Disse queeu não podia maister filhos. Eledisse: "Eu fechei a sua fábrica".

Muito embora seja perfeitamente possível que o médico tenha encontrado razões clínicas para proceder à cirurgia, e muito embora ele possa ter resolvido um problema para ela, chamou a atenção que a paciente tenha sido comunicada sobre uma intervenção em seu próprio corpo, seis dias após o procedimento ter sido realizado.

Com relação aos aspectos positivos da esterilização, a maioria da mulheres (23) das mais variadas idades, ocupações e nível de escolaridade apontaram a tranqüilidade que adquiriram a partir da certeza de que não vão mais ter filhos, e não vão mais ter que se preocupar com outros métodos. Dentre estas, sete mulheres, seis das quais com quarenta anos, indicam como vantagem a tranqüilidade da vida sexual com o marido. Uma delas inclusive argumenta que melhorou seu estado geral de saúde a partir da esterilização em virtude destas despreocupações.

Ao dialogar sobre os aspectos negativos da esterilização, as mulheres colocaram em primeiro lugar os problemas de saúde que passaram a sentir depois da cirurgia, pois consideraram que estes problemas interferem tanto na sua vida social quanto afetiva. Dentre as 40 in- vestigadas, onze (sete no Grupo I e quatro no Grupo II) afirmaram ter passado a sofrer dos seguintes problemas: distúrbios menstruais (cólicas, fluxo abundante e irregular), dores nos seios, dores abdominais, distúrbios emocionais, dores de cabeça constantes e perda da vontade sexual; 4 delas admitiram ter percebido apenas alterações menstruais que não interferem nos demais aspectos de sua vida. Enquanto isto, 15 no Grupo I e 14 no Grupo II constataram que a experiência no geral tem sido positiva.

Tendo em vista a existência de uma proporção considerável de mulheres que perceberam alterações de saúde que têm afetado sua disposição social, sexual e afetiva, considera-se oportuno relatar brevemente seus depoimentos, destacando suas representações sobre o período pós-esterilização, a fim de melhor esclarecer sobre as ambivalências e dilemas implicados na experiência da contracepção de modo geral e da esterilização em particular, bem como a fim de resgatar como percebem as reações dos agentes médicos antes e após a cirurgia. Iniciando pelas narrativas do Grupo II, encontraram-se quatro casos de experiências negativas, sendo que todas realizaram laparotomia ampla por ocasião da cesariana em hospital público.

Marta tem 42 anos, está realizando curso superior e é casada com um profissional liberal. Tem 03 filhos, foi esterilizada em hospital público quando tinha 27 anos de idade. Tomou a decisão com base em conversas com o médico e com o marido. Sobre sua percepção acerca de sua condição de esterilizada comenta: "sinto dores em virtude de aderência, e sinto que não poder procriar afeta a mulher. A menopausa chega mais cedo". Os médicos que consultou admitem "que os problemas têm a ver com a esterilização. Inclusive acham isto normal."... "Sinto raiva. Se fosse hoje, eeu soubesse sobreas conseqüências, não faria".

Dora tem 34 anos, funcionária pública, dois filhos, fez curso superior e seu marido é empresário. Foi esterilizada aos 26 anos. A respeito de sua condição atual afirma: "quando fui fazer o parto, não ti nha certeza de queia fazer ligadura. Fiz por indução médica. O parto ia ser normal, mas senti que uma enfermeira forçou a ruptura da bolsa, obrigando a fazer uma cesariana." Após este fato, "o médico comentou sobre a ligadura. Como eu não queria mais ter fiIhos aceitei, mas sinto quefoi tudo muito rápido."... “Durante o período menstrual sinto dor no mesmo local ondefoi feita a cirurgia."... “o médico não deu importância, embora este problema interfira na vida sexual..." 
Sônia tem 30 anos e está cursando o nível superior. É funcionária pública e o marido também. Tem dois filhos e foi esterilizada aos 24 anos: "o marido queria fazer vasectomia, mas eu não queria mais ter fil hos eoptei pela laqueadura"... "hoje enfrento distúrbios hormonaise sei os inchados"... "quando vou ao médico, eles nem perguntam se eu sou esterilizada".

Vera tem 43 anos, realiza curso superior, é funcionária pública estadual assim como o marido. Tem três filhos e teve um aborto natural. Foi esterilizada com 27 anos e decidiu junto com o marido. Acha que o seu "organismo não aceitou a laqueadura."... “sinto cólicas fortes, aumento do fluxo e nervosi smo. Fiquei sexualmentefria. O médico disse que podia acontecer. Seeu pudesse voltar atrás, não faria".

No caso das sete mulheres que se sentem afetadas pela esterilização no Grupo I, seis realizaram a laparotomia ampla por ocasião da cesariana e uma realizou minilaparotomia após parto normal, sendo que apenas uma recorreu à clínica privada. São as seguintes as situações:

Inês tem 38, o segundo grau incompleto, é doceira e o seu marido é mecânico. Tem três fiIhos e foi esterilizada quando tinha 27 anos na terceira cesariana. "O médico sugeriu, mas eu também queria". Acerca dos seus problemas comenta: "a menstruação aumentou, os prazos adiantaram, si nto dores de cabeça." Sendo catequista e, portanto, católica praticante, seus conflitos aumentam: "não sei como fico perante Deus, porque a Igreja não consente" ..."tenho três irmãs etodas ligaram. Uma prima minha foi ligada com 22 anos. Todas sentem alguma coisa de ruim depois. Uma que ligou com 29 anos teve mi omas no útero depoi s da esterilização."

Glória tem 44 anos, cursou até o segundo ano primário, é dona-de-casa, teve três filhos e tem dois atualmente. Teve também um aborto natural. Foi esterilizada aos 36 anos. "Tive problemas de útero virado. Por mim não ligaria as trompas, mas o médico disse que era necessário. Não escolhi. Depois de sete meses com a barriga dolorida o médico disse que era normal. O mé dico é burro. Problemas não podem ser normais"... A esterilização tem, segundo ela, interferido na vida sexual: "não tenho nenhuma vontade. Por mim nunca teria feito. Perguntei ao meu companheiro o que ele achava de estar com uma mulher vazia por dentro... elenão disse nada... me sinto culpada por não ter quase relações com ele."

Gorette tem 26 anos, cursou até o terceiro ano primário, é dona-de-casa, e o seu marido é ferreiro. Tem quatro filhos e diz que tomou "pí-
Iula por algum tempo, mas não passava bem". Foi esterilizada com 24 anos porque "não que ria mais ter filhos. Pedi ao médico e ele avisou que podia ter problemas porque eu era muito nova. Tive quevoltar ao hospital porque eledeixou restos da placenta lá dentro. Fui operada outra vez. Sinto cansaço, dores dos lados até ao deitar e dores na bexiga. Tenho pouca disposição para a vida sexual. Não sei se isto tem que ver com a esterilização, mas sei que não sentia isto antes."

Carla tem 41 anos, é dona-de-casa, fez até o quarto ano primário, o marido vende caldo de cana, tem dois filhos. Foi esterilizada dois anos após o último filho, por ocasião de outra cirurgia, aos 32 anos, porque "não podia maistomar comprimido porque me sentia muito mal. O médico disse que podia haver problema. Eledisse quea ligação não faz bem para ninguém, traz problemas para as mulheres com o passar dos tempos. Ele foi honesto. Meus problemas são nervosi smo e dores de cabeça."... "O atendimento no Posto é horrível. A médica disse que a dor de cabeça podia ser loucura, que era para procurar outro médico... Conheço outras mulheres queligaram que têm os mesmos problemas. Espero que com o passar do tempo os médicos possam resolver estes problemas."

Cora tem 42 anos, é espírita, cursou até a sexta série, é empregada doméstica, recebe até um salário mínimo, o seu marido é motorista, atualmente desempregado. Teve três fiIhos e três abortos provocados. Foi esterilizada com 23 anos durante a tercei ra cesárea. “Tive um fil ho atrás do outro, o médi co di sse que devia fazer". Agora ela aconselha "a não fazer a ligadura por que estou cheia de problemas. Te nho cisto no ovário, problemas de menstruação enão tenho vontade sexual. A esterilização prejudica o casamento devido à fal ta de sexo. O casamento esfriou. Além do mais gostaria deter tido uma filha. Já fiz várias cirurgias depois. Se soubesse queia ter problemas não teria feito."

Dalva tem 28 anos, freqüenta um curso técnico, é divorciada, trabalha como promotora de marketing e cria os três filhos porque o exmarido não quis assumir responsabilidades. Foi esterilizada aos vinte e três anos. "Todas foram gravidezes de risco. O médico aconsel hou a ligar. A decisão foi definitiva, após o térmi no do casamento. Meus problemas são depressão, he morragia, dores, aderência e cistos. O médico disse que eu já era nervosa antes, mas não se preocupa que eu piorei do nervosismo. Eleéinteressado, mas não está na minha pele. Sinto desinteresse pelos fil hos, agressi vidade edistanciamento das pessoas, mas se eu tiver outro casamento sinto não poder mais ter outros filhos." 
Cátia tem 25 anos, cursou até o quarto ano primário, é dona-de-casa e o marido é serraIheiro. Teve seis filhos, um aborto provocado, e foi esterilizada aos vinte e quatro anos "porque a pílula fazia mal" e "tinha certeza de não querer mais ter filhos, etinha vontade de ser outra mulher."... “tenho problemas, mas não culpo os médicos, a decisão foi minha, mas gostaria deter tido mais informações. Sinto dores de cabeça, perda da vontade sexual etambém desânimo e tristeza."... Sugere que sejam realizadas "palestras para as mulheres que pretendem se esterilizar". "Ora mearrependo, ora não"..."o meu marido diz queeu fiquei fria feito uma geladeira".

Chama atenção que enquanto 25 das 40 mulheres entrevistadas foram submetidas à esterilização após os 30 anos, dentre as onze que declararam que a ligadura provocou alterações na sua saúde, 9 tinham menos de 30 anos; entre estas últimas, 3 tinham menos de 25 anos quando foram laqueadas. Outros autores já tinham chamado a atenção do maior risco de arrependimento, com todas as suas conseqüências psicológicas e somáticas, quando a laqueadura era realizada em mulheres com menos de 30 anos, e mais ainda em menores de 25 anos (Pinotti et al., 1986).

Contrastando visivelmente com a condição destas onze mulheres foram encontradas situações em que o bem estar após a esterilização é indiscutível. É o caso de Aparecida, do Grupo II, que sente que sua vida mudou para melhor. Ela tem atualmente 32 anos, é católica, participa de movimentos religiosos na I greja, fez o magistério de segundo grau mas não leciona, dedica-se aos afazeres domésticos. Tem dois filhos e foi esterilizada aos 28 anos. Segundo ela, "a pílula era um horror. Tinha problemas sexuais e desaúde. Minha mãeeminhasirmãs já fizeram ligação. Tinha ferida no útero, fungos, depressão enervosi smo com o uso da pílula... Os meus problemas desapareceram totalmente, mel horou cem por cento a atividade se xual, me sinto mais livree sem medo."

Anal isadas as representações daquelas que não consideraram ter sofrido alterações em sua vida a partir da esterilização, perceberamse, além de sentimentos de bem estar semeIhantes a este, algumas situações que também merecem registro. Em quatro casos, como já se mencionou, observou-se que embora as muIheres tenham notado alterações do ciclo menstrual após a cirurgia (incluindo-se cólicas e fluxo abundante) não consideraram que isto tenha se transformado num problema de saúde para elas, desde quando, apesar disto, conseguiram dar conta de seus afazeres no trabaIho em casa e fora dela.
Uma das mulheres, atualmente com 46 anos, afirmou ter sentido apenas nos primeiros meses após a esterilização, "uma sensação de castração". Muito embora ela se sinta bem no geral, comentou ainda que, se soubesse da vasectomia antes, não teria sido ela a esterilizar-se, mas o seu companheiro.

Uma outra, atualmente com 40 anos e esterilizada aos 28, admitiu que teve uma quarta gravidez indesejada, "aproveitou o ensejo para fazer a laqueadura" e recorreu à esterilização porque andava "até com medo de deitar na cama com o marido e engravidar outra vez". Ela está entre as que se queixam de fluxo abundante.

Finalmente, uma das investigadas esterilizada aos 32 anos e atualmente com 46 e três fiIhos, incorporou de tal modo a cultura da esterilização que defende que este procedimento deveria ser realizado "nas mul heres pobres, para diminuir a miséria ea pobreza e também os bandidos". Absolutamente convicta sobre seu ponto de vista, ela parece não se dar conta de que a diminuição da prole, por si só, não representa uma garantia de melhora no padrão de vida sequer para si própria, pois seu marido, militar de baixa patente não consegue ganhar nem três salários mínimos mensais para sustentar a família, enquanto ela se esgota lavando, passando, cozinhando, arrumando, cuidando dos filhos e evitando qualquer despesa extra para a família. Tanto esta como outras situações similares levam a crer que a renúncia radical à maternidade, observável nos setores populares, estrutura-se de modo que não se lute para ter mais; em lugar disto, a meta se desloca no sentido de assegurar que o pouco que se tem seja suficiente para alimentar poucos, transformando-se nestes casos a esterilização num poderoso instrumento de acomodação.

\section{Considerações finais}

Os depoimentos das mulheres entrevistadas não são necessariamente representativos do universo das mulheres esterilizadas, visto que muitas não aceitaram participar do estudo. Não sabemos se o grupo que não aceitou participar o fez porque não tendo nenhuma queixa, não sentiu necessidade de "denunciar" esses maus resultados através da pesquisa, ou se, pelo contrário, a laqueadura trazia para elas experiências tão negativas que não desejaram relembrá-las durante a entrevista. Assim, os depoimentos citados devem ser considerados apenas como exemplo do que pode acontecer na vida das mulheres laqueadas, sem que se 
possam tirar conclusões referentes à freqüência relativa com que estas conseqüências positivas e negativas possam acontecer. Os resultados desta pesquisa, no entanto, possibilitam a elaboração de considerações finais acerca de vários aspectos. Inicialmente cabe ressaltar que o perfil das mulheres investigadas confirma certas características existentes em nível nacional, com relação à idade, ocupação, tipo de esterilização, utilização anterior de outros métodos contraceptivos, escolaridade, número defilhos, etc.

Com base nos dados a respeito destas características torna-se possível entender que a opção pela esterilização tem avançado de tal modo que até certo ponto independe daquelas variáveis, visto que tanto mulheres com apenas um filho, quanto mulheres muito jovens, com diferentes ocupações e distintos graus de informação, têm optado por fazê-la como uma solução radical de contenção da natalidade.

Esta opção, porém, necessita ser contextualizada, uma vez que, embora muitas vezes as entrevistadas mencionem que solicitaram a cirurgia, esta escolha conforme lembra Barroso (1984:170), na medida em que implica contraditoriamente tanto a liberdade quanto a opressão, "ocorre dentro de um conjunto de alternati vas que elas individualmente são impotentes para alterar"; estas alternativas decorrem de determinantes sociais, dentre os quais se destacam "a posi ção desvantajosa da mulher na família e no mercado de trabalho, a cultura patriarcal, a política de mercantilização da saúde e política demográfica".

A partir da base de dados, torna-se possível também inferir que a cultura patriarcal, somada à influência dos meios de comunicação de massa, continua operando a fim de fazer com que recaiam principalmente sobre a mulher as responsabilidades tanto com a criação dos fiI hos e a manutenção da casa, quanto com os cuidados com a contracepção, independentemente, como se sabe, do fato de que ela trabaIhe fora de casa. Ao mesmo tempo esta cultura impele a mulher a escolher o método "menos conspí cuo, o mais garantido e o menos dependente da cooperação masculina", tentando-se garantir desta forma para o casal, além do controle sobre os nascimentos, a segurança, a liberdade e o prazer (Barroso,1984:174).

Talvez em virtude destas expectativas, o surgimento inesperado de problemas de saúde posteriores à esterilização, afete sobremaneira a disposição de algumas mulheres incluídas no presente estudo, quando elas se dão conta de que ao resolver para a família a questão da contracepção, têm que enfrentar outros impas- ses ligados ao mal-estar provocado pela solução que se encontrou.

Deste modo é possível concluir que a discussão sobre a contracepção deve ser referenciada à perspectiva de gênero, na medida em que faz parte da construção social e cultural do masculino e do feminino, compreendendo-se, portanto, o corpo como produção social e cultural "mediada por uma série de instituições" (Menicucci de Oliveira, 1991:04).

Dentre estas instituições, destacam-se evidentemente as médicas, tendo sido possível perceber através dos depoimentos das mulheres, que ao mesmo tempo em que estas instituições interferem na escolha, comportam-se de modo ambivalente antes e após o surgimento de problemas de saúde. Neste caso talvez a desinformação das mulheres sobre as possíveis conseqüências negativas da esterilização resulte não apenas de uma possível falta de ética ou motivações lucrativas de alguns profissionais da saúde (e de suas convicções acerca do controle da natalidade e da esterilização como meio de evitar o aborto e diminuir a mortalidade feminina), mas de uma desinformação e de uma falta de consenso da própria área médica a propósito destas conseqüências (M inella, 1996).

No caso da presente pesquisa, esta desinformação atinge não apenas donas-de-casa de setores populares, com baixo nível de escolaridade, mas também professoras universitárias e funcionárias públicas de nível superior que tampouco foram informadas ou procuraram obter informações sobre possíveis conseqüências.

A este respeito, à luz dos resultados desta pesquisa, torna-se também possível averiguar que o avanço da esterilização se inscreve no marco de um processo que Vieira (1990:96) define como "naturalização da intervenção médica na esfera do comportamento reprodutivo", reforçando-se assim em escala ampliada, o papel social da medicina.

Este processo, por sua vez, de acordo com Vieira (1990:96), faz parte de uma estratégia de medicalização do corpo feminino, transformando o controle populacional em "uma questão que emerge não mais como questão de política demográfica, mas como problema para o qual são propostas resoluções cirúrgi cas ou gi necológicas" possibilitando-se por esta via "que a soci edade organize seus contingentes populacionais lançando mão do predomínio técnicocientífico para administrar a reprodução humana".

No caso brasileiro este tipo de administração se disseminou a tal ponto que Berquó (1994:16) caracteriza a queda da fecundidade 
no país como uma "queda cirúrgica", enquanto Giffin (1992:99) relaciona as mudanças no padrão reprodutivo das sociedades em desenvolvimento como um processo estreitamente vinculado ao contexto da "modernidade perversa", ou seja, da modernidade que impulsiona significativamente os avanços tecnológicos na área da contracepção sem avaliar devidamente as chances de risco para a saúde.

Os dados levantados nesta pesquisa permitem concluir ainda que a exemplo do que ocorre de maneira geral, o modelo da mulher reprodutora está sendo substituído por outro no qual a mulher, sabendo-se reprodutora, controla e até nega sua capacidade reprodutiva, como estratégia de sobrevivência (principalmente no caso do Grupo I) e como estratégia de afirmação em outros âmbitos (principalmente no caso do Grupo II).

De alguma maneira, a familiaridade das mulheres entrevistadas com a esterilização lembra os resultados encontrados no estudo de Citelli et al. (1995:24) que, ao analisar a trajetória reprodutiva de grupos de mulheres dos setores populares em diferentes regiões do país, concluem afirmando que "a esterilização pare ce ter se instalado de modo definitivo no curso de vida das mul heres como um momento "natural", o ponto de chegada de sua experiência reprodutiva. Passa-se, portanto, do ciclo biológico menarca-concepção-gestação-parto para um novo ciclo menarca-concepção-gestaçãoparto-esterilização, em que a despeito de ser uma intervenção externa sobre o corpo, a esterilização adquire o mesmo status dos outros momentos e, na sua concepção do ciclo, termina por "naturalizar-se".

Por último vale ressaltar que embora a objetividade do discurso das entrevistadas possa ser discutida (porque influenciada por uma série de determinantes sociais), isto não invalida, por si só, a veracidade das experiências percebidas após a esterilização, porque estas experiências são reais, em suas conseqüências, para aquelas que a vivenciam.

Por outra parte, é um legítimo direito das mulheres decidir sobre a ligadura tubária, quando em condições apropriadas de plena informação e autodeterminação. Nossos dados, entretanto, não permitem distinguir em que circunstâncias a ligadura representa um elemento de liberação, e em quais um fator de opressão, com efeitos negativos sobre sua vida, apesar que estes últimos parecem concentrarse nas mulheres mais jovens como já sugerido por outros autores (Hardy et al., 1996).

Ainda que nossos resultados também não permitam determinar em que proporção as mulheres vêem a ligadura como tendo efeitos positivos ou negativos sobre as suas vidas, nossos dados são importantes para orientar futuras pesquisas de tipo quantitativas que possam responder esta questão. Neste sentido, entende-se que considerar a percepcão das mulheres esterilizadas sobre si mesmas como um dado altamente significativo e esclarecedor, implicou abandonar uma posição de estrita confiança na ciência como a única fonte de conhecimento produtora de discursos confiáveis. Isto porque considerou-se que a objetividade dos discursos formulados pela prática científica sobre o tema pode ser igualmente questionada, haja vista a estreita vinculação entre ciência e poder observável neste caso, o que provavelmente se deve às sérias implicações econômicas e políticas que envolvem o tema e que certamente podem interferir tanto na condução quanto nos resultados das pesquisas. 


\section{Referências}

ALMEIDA, M. M. G., 1988. Status social e métodos anticoncepcionais. Revista Baiana de Enfermagem, 4:9-62.

BARROSO, C., 1984. Esterilização feminina: liberdade e opressão. Revista de Saúde Pública, 18:170-80.

BERQUÓ, E., 1994. Uma queda (cirúrgica) na fecundidade. Revista Imprensa, 76:16-20.

CARVALHO, J. A. M., 1994. Um Brasil mais velho e mais estável. Revista Imprensa, 76:07-11.

CITELLI, M. T.; SOUZA, C. M. \& PORTELLA, A. P., 1995. Reveses da anticoncepção entre mulheres pobres. XIX Encontro Anual da ANPOCS. (mimeo.)

CN (Congresso Nacional), 1993. Relatório Final da Comissão Parlamentar Mista de Inquérito Destinada a Examinar a "Incidência de Esterilização em Massa de Mulheres no Brasil". Brasilia: CN.

COSTA, S. H.; MARTINS, I. R.; PINTO, C. S. \& FREITAS, S. R. S., 1989. A prática de planejamento familiar em mulheres de baixa renda no Município do Rio de Janeiro. Cadernos de Saúde Pública, 5:169-186.

COSTA, S. H. \& PINTO, C. S., 1989. Os efeitos demográficos da contracepção e a queda da fecundidade. In: Quando a pacienteé mulher. (ConseIho Nacional dos Direitos da Mulher, org.), pp. 85-90, Brasília: Conselho Nacional dos Direitos da Mulher.

FARR, R., 1994. Representações sociais: a teoria e sua história. In: Textos em Representações Sociais (S. Jovchelovitch \& P. Guareschi, orgs.), pp. 31-59. Petrópolis: Vozes.

GAZOLA, S. \& BOEIRA, V. L. G., 1992. Modificações no Perfil da Contracepção em Mulheres Usuárias do Serviço de Saúde da Costei ra do Pirajubaé após a Implantação do PAISM. Florianópolis: Centro de Ciências da Saúde, Universidade Federal de Santa Catarina. (mimeo.)

GIFFIN, K., 1992. A modernidade perversa e a reprodução humana no Brasil. In: Saúde, Ambiente e Desenvolvimento, Vol. II, (M. C. Leal, org.), pp. 99102. São Paulo: Hucitec/Rio de Janeioro: Abrasco.

HARDY, E.; BAHAM ONDES, L.; OSIS, M. J.; COSTA, R. G. \& FAÚNDES, A., 1996. Risk factors for tubal sterilization. Regret, detectable before surgery. Contraception, 54:159-162.
IBGE (Instituto Brasileiro de Geogragia e Estatística), 1994. Resultados do universo relativos às características da população e dos domicílios. Censo Demográfico 1991, Santa Catarina, n. 23. Florianópolis: IBGE.

JOVCHELOVITCH, S. \& GUARESCHI, P. 1994. Introdução. In: Textos em Representações Sociais. (S. Jovchelovitch \& P. GUARESCHI, orgs.), pp. 17-25. Petropólis:Vozes.

MARTINE, G., 1989. O mito da explosão demográfica. Ciência Hoje, 9(51):29-35.

MENICUCCI de O. E., 1991. O gênero na saúde: autodeterminação reprodutiva das mulheres. XV Encontro Anual da Associação Nacional de PósGraduação e Pesquisa em Ciências Sociais. Caxambú. (mimeo).

MINELLA, L. S., 1996. Reprodução humana: uma análise sociológica das abordagens clínicas sobre esterilização feminina. Saúde, 1:71-85.

OSIS, M. J. D.; HARDY, E. E.; SIM ÕES, I. R. S.; VERA, S. \& FAÚNDES, A., 1990. Laqueadura tubária nos serviços de saúde do Estado de São Paulo. Revista Brasileira de Ginecologia e Obstetrícia, 1:195-204.

PINOTTI, J. A.; DIÁZ, J.; DIÁZ, M. M.; HARDY, E. \& FAÚ NDES, A., 1986. Identificação dos fatores associados à insatisfação após a esterilização cirúrgica. Revista Brasileira de Ginecologia e Obstetrícia, 9:304-309.

SIMÕES, C. C. da S. \& OLIVEIRA, L. A. P., 1988. Perfil Estatístico de Crianças e Mães no Brasil. A Situação da Fecundidade: Determinantes Gerais e Características da Transição Recente. Rio de Janeiro: Instituto Brasileiro de Geografia e Estatística/ Fundo das Nações Unidas para a Infância/ Organização Panamericana de Saúde.

VIEIRA, E. M., 1990. Prática Médica e o Corpo Feminino. Dissertação de Mestrado, São Paulo: Faculdade de Medicina, Universidade de São Paulo. 